\title{
Raised histamine concentrations in chronic cholestatic liver disease
}

\author{
S D Gittlen, E S Schulman, W C Maddrey
}

\begin{abstract}
Pruritus is a frequent symptom in chronic cholestatic liver disease. To date, no single causative mechanism has been identified. We examined venous plasma concentrations of the known pruritogen, histamine, using a highly sensitive radioenzymatic assay in 42 patients with chronic cholestatic liver disease, and in normal controls. The mean plasma histamine level was significantly greater in chronic cholestatic liver disease patients (275 (117) $\mathrm{pg} / \mathrm{ml} ; \times(\mathrm{SD})$ than in controls $(140(72) \mathrm{pg} / \mathrm{ml}$, $\mathbf{n}=20)(\mathbf{p}<0.0001)$. No significant differences were found between histamine concentrations in the two chronic cholestatic liver disease subgroups: primary biliary cirrhosis and sclerosing cholangitis. Histamine concentrations were significantly greater $(p<0.01)$ in the pruritic (319 (132) $\mathrm{pg} / \mathrm{ml}$ ) as compared with the non-pruritic (227 (75) $\mathrm{pg} / \mathrm{ml}$ ) chronic cholestatic liver disease patients. The histaminase activity was equivalent in patients and controls. The finding of raised histamine concentrations in chronic cholestatic liver disease suggests in vivo mast cell activation and a potential role for its mediators in the pruritus characteristic of these disorders.
\end{abstract}

Pruritus is a common symptom in chronic cholestatic liver disease. In a recently published study of over 300 patients with two major cholestatic disorders, primary biliary cirrhosis and primary sclerosing cholangitis, $70 \%$ suffered with pruritus. ${ }^{1}$ Despite numerous investigations, the aetiology of the pruritus remains unclear, and multiple factors may be involved..$^{2-4}$ Theories implicating a role for bile acids in pruritus have been rejected in recent years, and the mechanism for the relief obtained by some patients from use of the exchange resin cholestyramine is yet to be adequately explained. ${ }^{23}$

We postulated that histamine, a well described pruritogen in mast cell mediated allergic disorders, may also play a role in the pruritus of chronic cholestasis. ${ }^{5}$ To test this hypothesis, we determined plasma histamine concentrations in both pruritic and non-pruritic patients with either primary biliary cirrhosis or primary sclerosing cholangitis as well as a control group without liver disease or pruritus. We found that plasma histamine concentrations are raised in patients with chronic cholestatic liver disease. These findings implicate mast cell activation as an aetiologic factor in the cause of the pruritus in patients with chronic cholestatic liver disease.

\section{Methods}

\section{SUBJECTS}

Forty two patients with cholestasis (33 women and nine men) were seen at The Thomas Jefferson University Hospital. These patients had a diagnosis of either primary biliary cirrhosis or primary sclerosing cholangitis. Thirty of the 42 patients had antimitochondrial antibodies positive and had liver biopsies compatible with primary biliary cirrhosis. This subgroup was predominantly female $(93 \%)$ and had a mean age of $51.4(9.9)$ (SD) years. Eighteen of the 30 patients were symptomatic with pruritus and of these, 11 were receiving cholestyramine and one was treated with antihistamines at the time of testing.

Twelve patients with primary sclerosing cholangitis (seven men and five women) had a mean age of $39 \cdot 2(11.6)$ years. Four of the 12 had pruritus and one was being treated with cholestyramine. The diagnosis of primary sclerosing cholangitis was confirmed by endoscopic retrograde cholangiograms in all. Eight patients with primary sclerosing cholangitis had a concurrent diagnosis of inflammatory bowel disease: six with ulcerative colitis and two with Crohn's disease.

The mean age of the entire chronic cholestatic liver disease group was 47.9 (11.7) years (range 23 to 71 years). Of these 42 patients with chronic cholestasis, 22 complained of pruritus and 20 did not. The mean age of the patients with pruritus (46 (9) years) was similar to those who did not have pruritus (50 (14) years). Because biochemical parameters and plasma histamine concentrations were not significantly different in primary biliary cirrhosis and primary sclerosing cholangitis patients (see results) they were combined to further analyse the pruritic and nonpruritic cholestatic subgroups.

The control group consisted of 13 female and seven male volunteers who had no history of liver, dermatologic, allergic, or other systemic disorders. The mean age of controls was 38.8 $(14 \cdot 3)$ years.

\section{SAMPLE COLLECTION}

Venous blood was collected from all subjects in an upright non-fasting state. Samples were drawn into EDTA-containing tubes, refrigerated at $4^{\circ} \mathrm{C}$, centrifuged at $1100 \mathrm{~g}$ for 10 minutes, and plasma removed within four hours of collection. Timed studied in our laboratory have shown the stability of plasma histamine in venous specimens refrigerated for up to five hours before the separation of plasma. Samples were stored at $-20^{\circ} \mathrm{C}$ until analysed. 
PLASMA HISTAMINE ASSAY

Plasma samples were assayed for histamine using a recently described highly sensitive and specific radioenzymatic assay. ${ }^{67}$ The assay is sensitive to histamine concentrations of less than $50 \mathrm{pg} / \mathrm{ml}$ plasma or $1.2 \mathrm{pg}$ histamine added. The measurement of histamine is based on its conversion to a tritiated $\mathrm{N}$-methylhistamine by a purified rat kidney histamine $\mathrm{N}$-methyltransferase (HNMT) using $\left({ }^{3} \mathrm{H}\right) \mathrm{S}$-adenosylmethionine (New England Nuclear Corporation, Boston) as the methyl donor.

All plasma samples were run in duplicate along with aqueous blanks. Each plasma sample was also run with an internal standard consisting of an aliquot of plasma spiked with $500 \mathrm{pg}$ histamine. This point corresponded to the upper end of the linear portion of the standard curve. By quantitatively comparing the methylation of the plasma sample to the internal standard, the plasma histamine level of each sample was determined. Standard concentrations of histamine in water, or repeated aliquots of a single plasma sample, were tested to determine interassay variation. For plasma and aqueous specimens containing histamine in the range of 100 to 500 $\mathrm{pg} / \mathrm{ml}$, the interassay coefficient of variation was $18 \%$ which compares favourably with previously reported variations in double isotope ${ }^{89}$ and single isotope histamine assays. ${ }^{10}$ The intra-assay coefficient of variation was $6 \%$. Repeated assay of a single aliquoted plasma sample showed no degradation of histamine while stored frozen over a six month period.

\section{HISTAMINASE ACTIVITY}

Using a modification of the histamine assay, plasma histaminase activity was indirectly determined. By comparing the methylation of a 500 pg spike of histamine added to plasma to the same amount of histamine in water, the histaminase activity of plasma was determined. Histaminase activity was determined for each of the 42 cholestatic patients and 13 of the 20 controls and expressed as picograms of histamine degraded per minute of incubation.

\section{STATISTICAL ANALYSIS}

Results are presented as mean (SD). Comparisons between control and patient groups was performed using the Student's $t$ test for unpaired samples. A $p$ value of $\leq 0.05$ was considered significant. The relationship between plasma histamine concentrations and biochemical parameters (albumin and bilirubin) was analysed by linear regression analysis.

\section{Results}

The 42 patients with chronic cholestatic liver disease had a mean plasma histamine concentration of 275 (117) $\mathrm{pg} / \mathrm{ml}$ (mean (SD)). This was significantly greater $(p<0.0001)$ than the mean histamine concentration obtained for the 20 controls: $140(72) \mathrm{pg} / \mathrm{ml}$. The primary biliary cirrhosis and primary sclerosing cholangitis subgroups within our cholestatic population were analysed with respect to biochemical parameters
TABLE I Biochemical parameters of patients with primary biliary cirrhosis and primary sclerosing cholangitis

\begin{tabular}{lccll}
\hline & $P B C$ & $P S C$ & $p$ & Normal \\
\hline Bilirubin & $5 \cdot 2$ & $5 \cdot 2$ & $\mathrm{~ns}$ & $<1 \cdot 2 \mathrm{mg} / \mathrm{dl}$ \\
Albumin & $3 \cdot 8$ & $3 \cdot 5$ & $\mathrm{~ns}$ & $3 \cdot 3-5 \cdot 2 \mathrm{~g} / \mathrm{dl}$ \\
Alk Phos & 492 & 481 & $\mathrm{~ns}$ & $<95 \mathrm{IU} / \mathrm{l}$ \\
GGTP & 394 & 342 & $\mathrm{~ns}$ & $<25 \mathrm{IU} / \mathrm{l}$ \\
AST/ALT & $124 / 108$ & $167 / 159$ & $\mathrm{~ns} /<0.05$ & $<28 \mathrm{IU} / \mathrm{l}$ \\
PR ratio & 1.04 & 1.09 & $\mathrm{~ns}$ & $<1 \cdot 12$ \\
\hline
\end{tabular}

(Table I) and plasma histamine concentrations (Fig 1). No significant differences were seen in the biochemical parameters for these two diseases. The degree of hyperbilirubinaemia was similar with a mean concentration of approximately $5.0 \mathrm{mg} / \mathrm{dl}$. Hepatic synthetic function was generally well preserved in both groups as evidenced by normal mean serum albumin concentrations and prothrombin ratios. A five-fold rise in alkaline phosphatase, 15-fold increase in gamma-glutamyl transpeptidase and five- to sixfold increase in the aspartate aminotransferase were seen in both groups. Alanine aminotransferase, however, was slightly but significantly higher in the primary sclerosing cholangitis patients.

The mean plasma histamine concentrations in each chronic cholestatic liver disease subgroup was compared with an age and sex matched control subgroup, though within the entire control group, neither age nor gender correlated with plasma histamine concentrations. The 30 patients with primary biliary cirrhosis had a mean plasma histamine concentration of 297 (119) $\mathrm{pg} / \mathrm{ml}$ which was significantly greater $(p<0.01)$ than the control group which had a mean plasma histamine concentration of $136(81)$ $\mathrm{pg} / \mathrm{ml}$ (Fig 1). The 12 patients with primary sclerosing cholangitis had a mean plasma histamine concentration of 220 (97) pg/ml which was significantly greater than the concentration of $140(72) \mathrm{pg} / \mathrm{ml}(\mathrm{p}<0.05)$ in the control group There were no significant differences between the mean plasma histamine concentrations of the primary biliary cirrhosis and primary sclerosing cholangitis groups. Thus, the two cholestatic disease subgroups were not only biochemically similar but also had mean plasma histamine concentrations which were not significantly

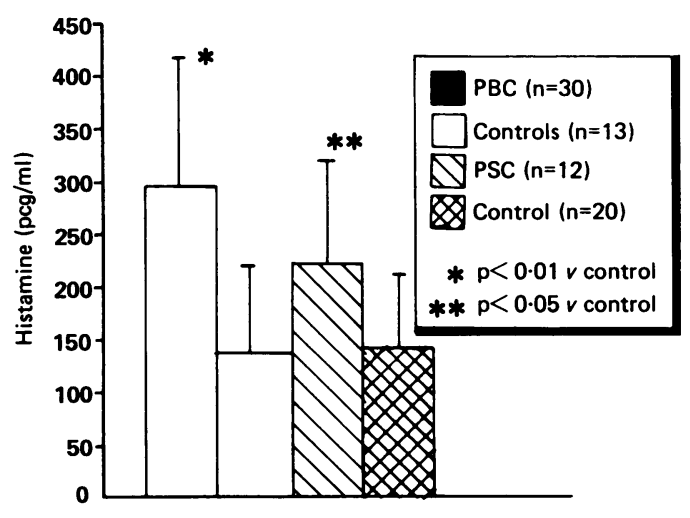
Study group

Figure 1: Mean plasma histamine concentrations in patients with primary biliary cirrhosis $(P B C)$ and primary sclerosing cholangitis (PSC) patients compared with their normal age and sex matched controls. ${ }^{\star}=p<0.01$ and ${ }^{\star \star}=p<0.05$ versus control group. 
TABLE II Biochemical parameters of pruritic and nonpruritic patients with cholestasis

\begin{tabular}{lccll}
\hline & $\begin{array}{l}\text { Pruritus } \\
n=22\end{array}$ & $\begin{array}{l}\text { No pruritus } \\
n=20\end{array}$ & $p$ & Normal \\
\hline Bilirubin & $7 \cdot 4$ & $2 \cdot 7$ & $<0 \cdot 02$ & $<1 \cdot 2 \mathrm{mg} / \mathrm{dl}$ \\
Albumin & $3 \cdot 5$ & $3 \cdot 9$ & $<0 \cdot 05$ & $3 \cdot 3-5 \cdot 2 \mathrm{~g} / \mathrm{dl}$ \\
Alk phos & 507 & 470 & ns & $<95 \mathrm{IU} / \mathrm{l}$ \\
GGTP & 390 & 389 & $\mathrm{~ns}$ & $<25 \mathrm{IU} / \mathrm{l}$ \\
AST/ALT & $164 / 140$ & $106 / 106$ & $\mathrm{~ns} / \mathrm{ns}$ & $<28 \mathrm{IU} / \mathrm{l}$ \\
PT ratio & 1.07 & 1.03 & $\mathrm{~ns}$ & $<1 \cdot 12$ \\
\hline
\end{tabular}

different from each other. We, therefore, included both patients with primary biliary cirrhosis and primary sclerosing cholangitis in one population for further analysis.

Comparisons of biochemical parameters, plasma histamine concentrations, and pruritus in chronic cholestatic liver disease patients were performed. Of 42 patients with cholestasis, 22 complained of significant pruritus. As shown in Table II, the patients with pruritus had significantly greater serum bilirubin concentrations $(p<0.02)$ and significantly lower serum albumin concentrations $(p<0.05)$ than patients who had no pruritus. Comparison of other markers of hepatic function, including alkaline phosphatase, gamma-glutamyl transpeptidase, prothrombin ratios, and the serum aminotransferases revealed no significant differences. Individual plasma histamine concentrations are shown in Figure 2. The cholestatic patients with pruritus had a mean plasma histamine level of $319(132) \mathrm{pg} / \mathrm{ml}$ which was significantly greater than the mean histamine level of non-pruritic patients $(227(75)$ $\mathrm{pg} / \mathrm{ml}, \mathrm{p}<0.008$ ).

The relationship between the higher concentrations of serum bilirubin and lower concentrations of serum albumin seen in the patients with pruritus was examined to determine if they significantly correlated with histamine concentrations. Neither bilirubin $(r=-0 \cdot 188)$ nor albumin $(r=-0 \cdot 120)$ significantly correlated with plasma histamine concentrations.

As previously noted, 12 of the 22 pruritic patients were taking cholestyramine at the time of testing. Cholestyramine therapy did not appear to lower plasma histamine concentrations with mean plasma histamine concentrations 312 (115) $\mathrm{pg} / \mathrm{ml}$ for the drug treated group $v 329$ (156) $\mathrm{pg} / \mathrm{ml}$ for the non-treated group.

Our recent studies in dialysis patients showed raised histamine concentrations despite marked increases in the histamine degrading enzyme, histaminase." This finding prompted a similar examination in the current study. Plasma histaminase activity, as reflected by the rate of histamine degradation in spiked plasma, was negligible in controls and in patients with cholestasis with or without pruritus.

\section{Discussion}

Our study shows the presence of raised plasma histamine concentrations in patients with chronic cholestatic liver disease. Of equal importance is the observation that pruritic patients with cholestasis have significantly higher plasma histamine concentrations than cholestatic patients without pruritus. The implication is that histamine, a well known pruritogen in other

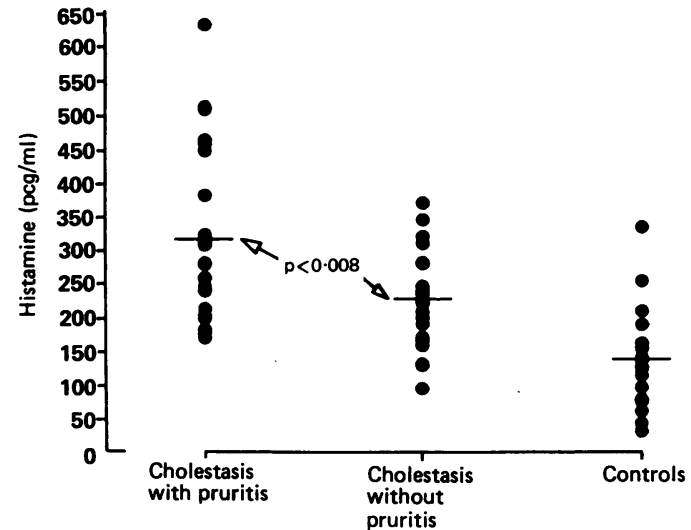

Figure 2: Plasma histamine concentrations in cholestatic liver disease patients with and without pruritus.

disease states, may play a role in the pruritus of cholestasis. ${ }^{5}$ Also, because histamine is a marker of mast cell activation, other potent mast cell mediators may also contribute to the pathophysiology of this symptom. ${ }^{12}$

To date, no single factor has been identified to explain the pathogenesis of pruritus in patients with cholestatic liver disease. Raised bile acids were formerly held to be the most likely pruritogen in cholestasis, a concept supported by the therapeutic success of cholestyramine. Neither serum nor skin tissue levels of bile acids, however, have been found to correlate with the presence of pruritus in chronic cholestasis. ${ }^{31}$ The role(s) of histamine and bile acids (or some other yet to be identified pruritogen) need not be mutually exclusive. Some investigators have hypothesised that bile acids act directly on tissue mast cells resulting in the release of histamine and the subsequent development of pruritus. ${ }^{14}$ Against this hypothesis is the current observation that among pruritic patients, the cholestyramine treatment group did not have lower plasma histamine concentrations than the noncholestyramine group. We did not, however, measure plasma histamine levels pre and post cholestyramine treatment which would be required to more rigorously evaluate this mechanism

The histamine measurements performed in the present study have been made possible by the development of a more sensitive and specific assay. ${ }^{67}$ As the radioenzymatic assay for histamine has been improved, the range of normal values for plasma histamine has declined by at least an order of magnitude and, the assay is now sensitive enough to measure fluctuations in plasma histamine which may occur clinically..$^{10}$ As a result of the new improved methodology, questions are raised about values for plasma histamine which relied on less sensitive assays. ${ }^{8}$

What then is the mechanism for raised plasma histamine concentrations in chronic liver disease? To answer this question, one must consider how histamine is formed and metabolised. Plasma histamine concentrations can be raised by the enhanced release of preformed histamine from tissue mast cells or circulating basophils. In these cells it is formed by the action of histidine decarboxylase on the amino acid histidine. Furthermore, plasma histamine might be increased by a decrease in the amount or 
activity of the predominant histamine metabolising enzymes, diamine oxidase (histaminase) and histamine $\mathrm{N}$-methyltransferase.

Evidence exists for increases in hepatic mast cell populations in both naturally occurring and experimental liver disease. As early as 1921, Staemmler described the presence of large numbers of mast cells in cirrhotic livers. ${ }^{16} \mathrm{He}$ found that mast cells proliferated in areas of increased connective tissue. This concept was supported by Umezu who produced a model of hepatic fibrosis by administering carbon tetrachloride to rats for 12 weeks and found increased numbers of mast cells in fibrotic foci surrounding Glisson's sheath, a finding which correlated with increased hepatic histamine concentrations. ${ }^{17}$ Hepatic mast cells have also been found in non-cirrhotic livers. Using special histochemical techniques, mast cell infiltration of the liver has been shown in systemic mastocytosis. ${ }^{18}$ Another pathway shown to increase hepatic histamine is by induction of histidine decarboxylase; endotoxin injection into guinea pigs resulted in hepatic enzyme induction and an increased rate of histamine formation ${ }^{18}$ Consistent with these observations, Ishii showed that treatment of chronic active hepatitis patients with a histidine decarboxylase inhibitor, resulted in lowering of baseline histamine levels. ${ }^{20}$ Unfortunately, as a normal control population was not studied, it is unclear if baseline plasma histamine concentrations were significantly raised in the patient group.

The role of histamine metabolising enzymes in human cholestasis is less certain. Barth showed no significant difference between the liver histamine $\mathrm{N}$-methyl transferase activity of control subjects and patients with cholelithiasis. ${ }^{21}$ To our knowledge histamine $\mathrm{N}$-methyl transferase levels in primary biliary cirrhosis and primary sclerosing cholangitis have not been previously studied.

Therefore, what is the clinical relevance of finding an association between raised plasma histamine concentrations and pruritus in chronic cholestatic liver disease? Previous authors have stated that histamine would appear to be an unlikely mediator of 'bile salt-induced' pruritus as antihistamines historically have yielded little relief in cholestatic itching. ${ }^{5}$ Antihistamines cause drowsiness and their dosage is frequently limited by central nervous system side effects. A study comparing the antipruritic efficacy of terfenadine, a non-sedating $\mathrm{H}_{1}$ blocker to cholestyramine, chlorpheniramine, and placebo in eight patients with either primary biliary cirrhosis or primary sclerosing cholangitis indicated that some patients benefited from terfenadine. ${ }^{22}$ This preliminary study combined with our observations provides a basis for larger scale trials to evaluate the newer antihistamines or putative mast cell stabilisers in the therapy of pruritus associated with chronic cholestasis.

This study was presented in part at the American Federation of Clinical Research in May 1986 in Washington, DC. An abstract of the paper was published in (Clin Res 1986; 34: 400A).

1 Wiesner RH, LaRusso NF, Ludwig J, Dickson ER. Comparison of the clinicopathologic features of primary sclerosing cholangitis and primary biliary cirrhosis. Gastroenterology 1985; 88: 108-14.

2 Garden JM, Ostrow DJ, Roenigk HH. Pruritus in hepatic cholestasis. Arch Dermatol 1985; 121 : 1415-20.

3 Freedman MR, Holzbach RT, Ferguson DR. Pruritus in cholestasis: no direct causative role for bile acid retention. Am F Med 1981; 70: 1011-6.

4 Schaffner F. Cholestryamine, a boon to some who itch. Gastroenterology 1964; 46: 67-9.

5 Herndon JH Jr. Itching: the pathophysiology of pruritus. Int $\mathcal{F}$ Dermatol 1975; 14: 465-83

6 Verberg KM, Bowsher RR, Henry DP. A new radioenzymatic assay for histamine using purified histamine $\mathrm{N}$ methyltransferase. Life Sci 1983; 32: 2855-67.

7 Verberg KN, Bowsher RR, Henry DP. Kinetic analysis of the histamine $\mathrm{N}$-methyltransferase reaction as used in the histamine radioenzymatic assay: optimization of assay histamine radioenzymatic assay: op
specificity. Life Sci $1984 ; 35$ : $241-51$.

8 Gleich GJ, Hull WM. Measurement of histamine: a quality control study. F Allergy Clin Immunol 1980; 66: 295-8.

9 Atkins PC, Valenzano M, Zweiman B. Plasma concentrations of histamine measured by radioenzymatic assay: effects of histaminase incubations. F Allergy Clin Imunol 1982; 69: 3945.

10 Sampson HA, Jolie PL. Increased plasma histamine concentrations after food challenges in children with atopic dermatitis. NEngl f Med 1984; 311: 372-6.

11 Goyal S, Gittlen S, Schulman ES, Burke JF, Besarab A Francos GC. Elevated histamine levels in uremia: effects of Fetotifen. Kidney Int 1987; 31: 233

12 Schulman ES. The role of mast cell derived mediators in airway hyperresponsiveness. Chest 1986; 90: 578-83.

13 Ghent CN, Bloomer JR, Klatskin G. Elevations in skin tissue levels of bile acids in human cholestasis: relation to serum level and to pruritus. Gastroenterology 1977; 73: 1125-30.

14 Little JM, Cage K, Oelberg DG, Lester R. Pathogenesis of cholestasis: an initial hypothesis. Hepatology 1985; 5: 1005.

15 Asad SI, Murdoch R, Youlten L, Lessof M. Plasma histamine levels in aspirin-sensitive urticaria. Ann Allergy 1987; 59. 219.

16 Umezu K, Yuasa S, Sudoh A. Change of hepatic histamine content during hepatic fibrosis. Biochem Pharmacol 1985; 34: 2007-11.

17 Staemmler $M$. Untersuchung uber vorkommen and bedeutung der histiogenen mastzellen in menschlichen bedeutung der histiogenen mastzellen in menschlichen krankf Z Pathol 1921; 25: 391 .

18 Yam LT, Chan CH, Li CY. Hepatic involvement in systemic mast cell disease. Am $\mathcal{Y}$ Med 1986; 30: 891.

19 Schayer RW. Evidence that induced histamine is an instrictic regulator of the microcirculatory system. Am F Physiol 1961; 202: 66-72.

20 Ishii K, Suzuk O, Maruyama K, Nagata H, Kiryu Y, Tsuchiya $M$. Therapeutic effect of histidine decarboxylase inhibitor in chronic active hepatitis. Gastroenterol f pn 1970; 13: 105-10.

21 Barth H, Kapp B, Crombach M, Priesack W, Lorenz W Histamine storage and metabolism of human liver in disorders of the biliary tract. Agents Actions 1980; 10: 101-4.

22 Duncan JS, Kennedy HJ, Trigor DR. Treatment of pruritus due to chronic obstructive liver disease. $\mathrm{BrMed} \mathcal{F} 1984 ; 289$ : 22. 